\title{
Influence of Enterprise Resource Planning Interface in Enhancing Service Delivery in Procurement Function at Geothermal Development Company, Nakuru
}

\author{
Lindah Jepchirchir Maiyo, Josphat Kwasira \\ College of Human Resource Development, Jomo Kenyatta University of Agriculture and Technology, Nakuru, Kenya
}

Email address:

maiyolinda8@gmail.com (L. Maiyo),jkwasira7@gmail.com (J. Kwasira)

To cite this article:

Lindah Jepchirchir Maiyo, Josphat Kwasira. Influence of Enterprise Resource Planning Interface in Enhancing Service Delivery in Procurement Function at Geothermal Development Company, Nakuru. Journal of Investment and Management.

Vol. 5, No. 5, 2016, pp. 70-81. doi: 10.11648/j.jim.20160505.15

Received: August 21, 2016; Accepted: September 21, 2016; Published: September 29, 2016

\begin{abstract}
The use of enterprise resource planning (ERP) software had become increasingly more common in a lot of today's businesses; it is adopted in many firms in attempts of improving business performance. The purpose of this study was to determine the influence of ERP interface on service delivery in procurement function of GDC. The study adopted descriptive research and was a case study. ERP interfaces were the independent variable while service delivery was the dependent variable. Procurement department of Geothermal Development Company, Nakuru was used as a case and consequently, employees of Geothermal Development Company Nakuru constitute the target population for the study. The study was guided by innovation diffusion theory and theory of constraints. The study involved employees from Procurement, Stores, Registry, Finance and ICT departments in the organization. 115 employees in the five departments constituted the target population for the study. 99 employees were selected through stratified random sampling to be involved in the study. Selected employees from the five departments were issued with questionnaires that contain research items on every research variable. The collected data were coded and analyzed by use of SPSS. The independent and dependent research variables were analyzed descriptively using means and standard deviation while the influence of ERP interface on service delivery was analyzed inferentially using regression analysis. A multiple regression model was developed and used to guide the study. The findings of the study were presented using tables and every table was explained. The study concluded that ERP interfaces both individually and collectively have significant influence on service delivery. The study recommended that ERP interfaces should be adopted by organizations to enhance service delivery. Further study were recommended to establish the role of organizational culture in adoption of ERP interfaces, to develop a theory that would explain the direct link between ERP and service delivery and to establish whether there are specific determinants of ERP adoption unique for manufacturing and service organizations.
\end{abstract}

Keywords: Enterprise Resource Planning Interface, Service Delivery, Procurement Function

\section{Introduction}

With the increasing competition and ever evolving technology that increases customer awareness and exposure, organizations whether public or private are exposed to increased pressure from external bodies. They are consequentially becoming increasingly concerned about their customers. With the development of new and advanced technologies, organizations are increasingly adopting the emerging technologies to enhance service delivery and competitiveness among the organizations.
The commonly adopted technologies to enhance customer service delivery are computer systems based are focused to exchange of information between the organization and its customers and suppliers. One such strategy is use of enterprise resource planning (ERP) (Rashid at al., 2002). Private organizations have taken the lead in adoption of current technologies in delivery of services to customers (United Nations, 2001). The public organizations have not been left behind. There are efforts across the world to improve service delivery in the public sector (Humphreys, 1998). This study intends to relate ERP with service delivery in the procurement 
department of EDC Nakuru.

'Enterprise Resource Planning (ERP) is a computer-based systems designed to carry out companies' major activity areas such as planning, production and customer service in a coordinated manner (Tadinen, 2005).

'It is a software systems for business management, encompassing modules supporting functional areas such as; planning, manufacturing, sales, marketing, distribution, accounting, financial, human resource management, project management, inventory management, service and maintenance, transportation and e-business' (Rashid at al., 2002). ERP concept developed from Material Requirements Planning (MRP) and Manufacturing Resources Planning (MRP II).

The concept of ERP emerged in the late 1980s targeting majorly complex business organizations. The main idea behind development of ERP was the need to take care of the information needs of the complex organizations in a sufficient manner, to improve business productivity, eliminate wastages, improve organizational internal effectiveness and improve inbound and outbound logistics. ERP become more relevant during this time as most organizations were getting more exposed to global competition and getting exposed to complex business environmental conditions such changing customer needs, changing regulations and internal standards (Rashid, 2002).

Enterprise Resource Planning has gained popularity because it is associated with a number of advantages to the organization. Rashid at al. (2002) identified a number of benefits of ERP. These benefits include; reliable information access, reduced data and operational redundancy, timely delivery and cycle time reduction, reduced wastages and costs, improved scalability, improved maintenance, enhanced market access and e-business. According to Umble et al. (2002), ERP leads to improved human resource management, enhances supply chain management, improved customer relations management, enhances finance management and in turn improved customer satisfaction.

Irrespective of the nature of an organization, literally all organizations have customers. According to Mum, (2015), customer is anyone interested in the organization's products or services. Customers are categorized into internal and external customers. Internal customers are the employees in the organization while external customers are the buyers or users of the organization's products or anyone just interested in the organization and its products (Ching Yeh, 2005). Every organization must therefore be interested in customer service.

Customer service is the provision of service to customers before, during and after a purchase of physical product or delivery of a service. The concept of customer service delivery has become a matter of concern to every manager in the current organization. As pointed out by Wernerfelt et al. (1996), customers are the starting and end point of an organization. He points out that organizations need customers to survive and therefore customers must be at the center of everything and organizations must strive to create and give value to customers. While organizations are expected to deliver quality and optimal service to customers, the expectations of customers are varied. It is therefore important that the necessary steps are taken so that customer's needs are understood and delivered (Riordan, 2003).

In India, to enhance service delivery in the public health sector, community score cards in primary health care services were introduced in Andhra Pradesh. This was in attempt to bring a link between the self-evaluation of providers and the evaluation of communities (Joshi, 2010).The concept of service delivery has become equally popular among scholars. Globally, a number of studies have been conducted on service delivery. For instance, Oosterom (2007) compiled a report titled 'the road ahead for public service delivery'.

The study focused on delivery of customer service as promised by organizations in the public sector around the world. The report looked at customers in terms of citizens and organizations that get served by public organizations (Oosterom, 2009). A similar study was conducted by The World Bank in the year 2012 to assess the use of social accountability approached in the human development sectors. The report appreciated that the there is growing efforts by governments, donors, and civil society alike to improve customer service and value for money in public organizations (Ringold, 2012).

In Africa, similar studies have been conducted. Joshi (2010) conducted a study on impact and effectiveness of transparency and accountability initiatives in delivery of customer service. The study reported that many countries in Africa have embarked on enhancing customer service delivery. The World Bank report revealed that Malawi for instance, the Civil Society Coalition for quality in Basic Education has used PETS three times to achieve impact, improving its methodology to enhance service delivery in schools (The World Bank, 2004). In Uganda, in an attempt to enhance service delivery in the health sector, the government introduced the use Citizen Report Cards, moving away from satisfaction surveys that were used earlier to enhance objectivity in service delivery in public hospitals (Ugandan Delivery of Improved Services for Health, 2003).

Geothermal Development Company (GDC) is a fully state owned state corporation in Kenya developed based on the government's policy on energy - Sessional paper No. 4 of 2004, and the energy Act No.12 of 2006. GDC was formed in 1957 with the mandate of harnessing geothermal resources to supplement the traditional hydro-electric power.

Among the five mandates of the company are; management of geothermal reservoirs to ensure constant supply of steam for power generation and promotion of alternative uses of geothermal resources other than electricity generation such as; greenhouse heating, drying of grains, pasteurizing milk, cooling and heating of rooms. To achieve its mandate, the company has put into place initiatives to ensure resources are available in the right quantity, quality and time both for its operations and to customers. One such initiative is the use of information system to link the company with its suppliers and customers (Geothermal development Company, 2016). This study investigated the effect of ERP interface on service 
delivery in state corporations in Kenya.

\subsection{Objectives of the Study}

i. To determine the influence of Business to Suppliers Interface on Service Delivery in procurement department at GDC, Nakuru.

ii. To establish the influence of Business to Consumers Interface on Service Delivery in procurement department at GDC, Nakuru.

iii. To determine the influence of Single Point interface on Service Delivery in procurement department at GDC, Nakuru.

iv. To establish the combined effect of business to suppliers interface, business to consumers interface and single purpose interface on Service Delivery in procurement department at GDC, Nakuru.

\subsection{Hypotheses of the Study}

Ho1: Business to Suppliers Interface does not have significant influence on Service Delivery in procurement department at GDC, Nakuru.

Ho2: Business to Consumer Interface does not have significant influence on Service Delivery in procurement department at GDC, Nakuru.

Ho3: Single Point Interface does not have significant influence on Service Delivery in procurement department at GDC, Nakuru.

H04: Business to Suppliers Interface, Business to Consumers interface and Single Purpose interface collectively do not have significant influence on Service Delivery in procurement department at GDC, Nakuru.

\section{Literature Review}

\subsection{Theoretical Review}

This section presents the theories that guided the study. The study was guided by the theory of innovation diffusion and theory of constraints discussed below.

\subsubsection{Innovation Diffusion Theory}

Innovations Diffusion Theory was first published in 1962 by Professor Everett Rogers in his book 'Diffusion of Innovations' to explain how, why, and at what rate new ideas and technology spread. This theory explains that adoption of an innovation or technology is the adoption of the best course of action among the available alternatives so as to best achieve the needs of an organization and competitiveness. Rogers (2003) points out that diffusion of innovation has four components; innovation, communication channels, time, and a social system. He defines Innovation as an idea that is perceived as new by an individual or an organization of adoption.

The newness characteristic of an idea is related to knowledge, persuasion, and decision of the innovation-decision process. For any new adoption to be made there is need for flow of information. Communication is the exchange of information between two or more individuals or functional areas in an organization so as to reach a mutual agreement on adoption of new technology. The third concept of innovation diffusion is time that appreciates that technology keeps changing and so is its appropriateness and use. Lastly, an organization must be looked at as a social system "a set of interrelated units engaged in joint problem solving to accomplish a common goal" (Robinson, 2009).

The theory of innovation diffusion appreciates that the level of acceptance and adoption of new technology vary between organizations. Rotich et al. (2016) categorizes innovation adopters into four categories; Early Adopters, people who represent opinion leaders, Early Majority individuals who need to see evidence that the innovation works before they can adopt it, Late Majority, skeptical individuals who only adopts an innovation after it has been tried by the majority and Laggards, individuals who are very skeptical of change and are the hardest group to involve in the innovation process.

In this study, the theory of innovation helped in understanding the process of adoption of innovative systems like ERP. The theory appreciates that innovative strategies are informed by certain needs in the organization such as need to improve organizations' competitiveness, need to improve economic performance, need to increase sales, need to enhance service delivery among others (Rotich, 2016). This theory therefore provided a link between adoption of ERP and enhancement of service delivery thereby providing a conceptual link in the study.

\subsubsection{Theory of Constraints}

The theory of constraints (TOC) is a management philosophy that was introduced by Elijah M. Goldratt in 1984 in his book 'The Goal' (Goldratt, 1990). This theory appreciates that organizations operate in environment of limitations (constraint) and advocates that managers should focus on effectively managing the capacity and capability of these constraints if they are to improve the performance of their organization. TOC brings on board new management thinking. It brings the following concepts on board; new measuring system for organizational assessment, procedure for continuous process improvement and strategic decision process focusing on global rather than local issues. It also brings insight of advanced method for analyzing the relationships between resources and processes and determining where to focus the company's efforts, new methods for analyzing policy problems to arrive at simpler solutions; and new management approach for providing strategic and tactical direction (Institute of Management Accountants, 1999).

In the current business environment, there is increasing pressure on the need to ensure sustainability, with the scarcity of resources and limitations and constraints within and from outside the organizations, organizations must appreciate the need to make decisions that allow achievement of organizational goals within the capacity of the organization (Barnard, 2015). Adoption of innovative systems such as ERP requires intensive resources strategic changes within the 
organization. In addition, adoption of ERP requires training of employees and development of appropriate culture to embrace the change (Balderstone, 2015).

In this study, the TOC brought an understanding that in adoption of ERP, management of organizations must appreciate that the organizations operations and ability are limited by factors from within or outside the organizations (constraints) (Ricketts, 2008). Management must make the right decisions and adopt the right strategies to as to produce the right products in the most efficient way and avoid wasting time on the constraints. Despite the existence of constraints, customers still expect superior service from organizations and must get it.

\subsection{Empirical Review}

This section reviewed literature from past studies that have linked ERP implementation with service delivery. It linked the three dimensions of ERP; Business to Business Interface, Business to Customer Interface and Single Purpose interface with Service delivery.

\subsubsection{Concept ERP Implementation}

According Tadinen (2005) discussed five phases of ERP implementation. The first phase is design. This phase involves change of business processes and reengineering of the entire organization in readiness to adopt new ERP system. The second phase is implementation and involves training staff on their role on ERP implementation and developing a step-by-step procure on development of ERP based on the organization's size and needs. The third phase is stabilization and involves putting into place the processes that were planned and adjusting the organization's environment to accommodate the new change. This stage requires close monitoring and evaluation.

The fourth stage is continuous improvement. To enhance the effectiveness of ERP system, there is need to keep adding new modules and other improvements such as electronic data interchange, sales automation, warehousing and transportation capabilities, sales forecasting etc. This stage may also involve redesigning and reengineering. The last phase is transformation that involves reviewing the organization's needs and environment and continually putting into place the required change for successful implementation of ERP.

The five phases discussed by Tadinen (2005) were merged by Seaman (2012) into four phases. The first phase is discovery that involves; getting business group support, determining scope and priorities, reorganizing the organization strategically and organizing for program management. The second phase is proof of the concept that involves; establishing governance and development of standards, installation of base platform, validation of sequence and development of appropriate skills. The third stage is initial deployment that involves; ensuring readiness in terms of risk management, development and validation of support model and modeling business process. The last phase is scale and ramp that involves building of appropriate infrastructure and support teams and extend services. Figure 1 outlines the phase of ERP implementation as discussed by Seaman.

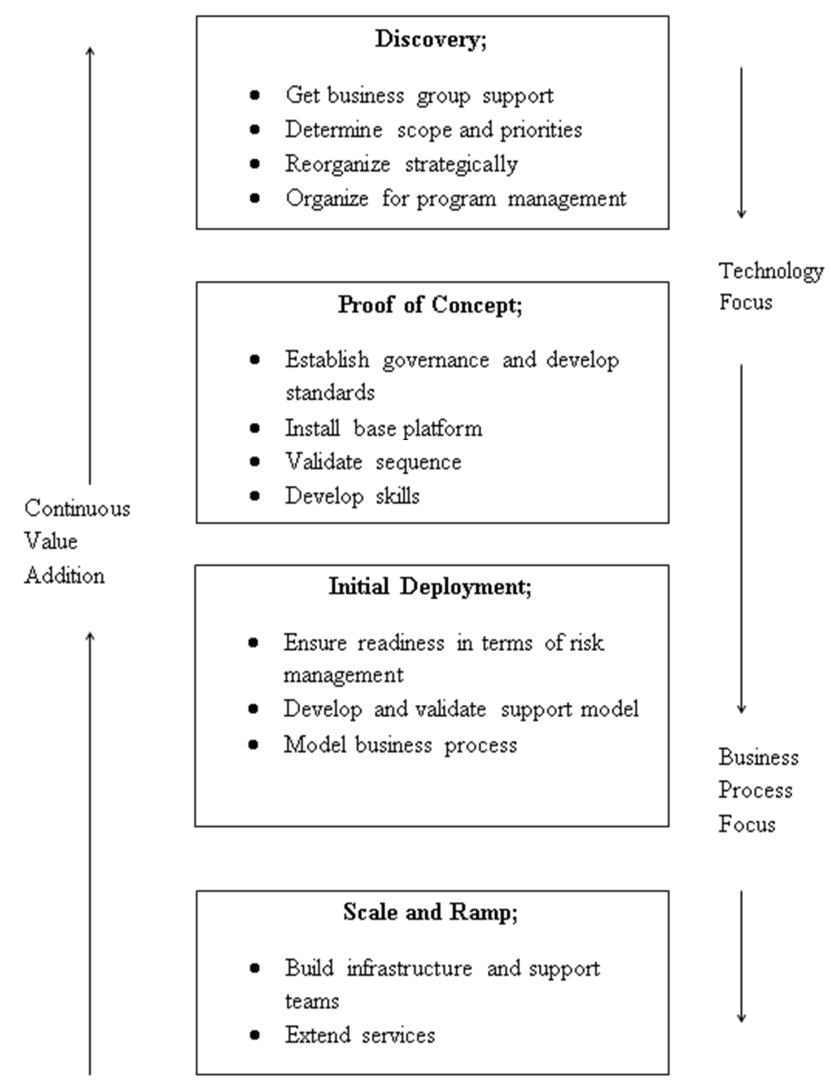

Figure 1. Phases of ERP Implementation.

Source: Seaman (2012)

According Seaman (2012), ERP implementation requires three main factors to succeed. The first factor is good governance. This is required for proper architecture and implementation of the ERP process. The ERP program leaders should have appropriate skills to be in a position to align business groups and decisions so as to come up with the desired outcome. They must also be in a position to prioritize and make objective funding decisions for the ERP system to succeed. The second factor appropriate skills. The ERP implementation team must have the required skills to be able to manage ERP resources appropriately and make appropriate ERP implementation decisions. Lastly, there is need for continuous planning and review of ERP transformation process.

\subsubsection{Business to Suppliers Interface}

According to Tadinen (2005), Business to suppliers interface is a computer-based system designed to link the organization with other organizations which could be suppliers, competitors, customers or public stakeholders. It is a computer package that has different modules for various business functions such as customer service, process control, financial and accounting management with respect to external organizations. Business to Business ERP interface integrates all functional areas in the organization (Ndungu, 2015). Development of business to business ERP system requires close cooperation between the business and IT organizations 
regarding ongoing management of the organization's ERP systems (Hebert, 2016).

Business to business ERP interface is developed to provide direct communication link between two or more organizations. This interface links the organization to its suppliers and customers (Sivak, 2014). Business to Business ERP systems provides seamless integration of all information flow of information between the organizations (Ndungu, 2015). Development of business to business ERP system requires close cooperation between the business and IT organizations regarding ongoing management of the organization's ERP systems (Hebert, 2016). Study on 'the effects of Enterprise Resource Planning Systems on Firm's Performance conducted in Commercial Banks in Kenya revealed that business to business ERP systems provide economical sharing of information between organizations thereby enhancing their operations. For service organizations, business to business ERP systems allow efficiency in flow of services especially where services can be offered through online media (Njihia, 2014).

The study recommended that a study should be conducted to establish if there is any direct link between specific functions ERP interfaces and customer service delivery. Enterprise Resource planning system attributes have significant influence on service delivery to stakeholder organizations. Development and use of ERP interfaces enhances quality utilization of resources within the organization. The enhanced information exchange and real time feedback leads to improved relationship between organization and customers and reduce customer complaints. Use of ERP interfaces also leads to increased efficiency, process improvements and improved resource management. To achieve desired levels of service delivery in institutions, use of adequate mix of both internal and external expertise is required in implementation of enterprise systems.

In addition, ERP deployment should be undertaken when sufficient critical success factors are addressed to position an institution favorably in successfully implementing an ERP system (Ndungu \& Wangombe, 2012). Use of ERP interface links the organization to suppliers enhances sharing of information. With the enhanced sharing of information, it is possible to reschedule orders and delivery, cancel orders, speed up orders and even speed up deliveries (Musyoka, 2012). Study on impact of ERP system in healthcare by Sanja (2013) use of ERP can be used to integrate the organization with its suppliers and customers especially where the business is considering e-commerce. Internally, ERP system application enhances routine operations of the organization. It allows easy and immediate access to information regarding inventory, product or customer data, and prior history information thereby enhancing service delivery.

\subsubsection{Business to Consumers Interface}

Business to customer interface links the organization with its customers (Riordan, 2003). Business to customer interface is based on the premise that organizations need customers to survive and therefore customers must be at the center of everything and organizations must strive to create and give value to customers. Business to customer interface facilitates real time flow of information between the organization and its market. It provides two way communications and provides feedback mechanism to enhance service delivery (Bazhair\& Sandhu, 2015).

According to Ndungu\&Kyalo (2015) conducted a study to establish how ERP based communication affects implementation experiences for various public universities in Kenya. The study revealed that the public universities in Kenya had adopted to a good extent ERP systems in their communication especially with external customers such as suppliers and clients. The study revealed that adoption of ERP in communication was a critical component of customer service as customers were more satisfied where services were offered through ERP platforms.

These findings are in agreement with the argument of Sanja (2013) that ERP allows organization to better connect with suppliers, distributors and customers to engage in e-business enhancing service delivery. Bazhair \& Sandhu (2015) conducted a study to assess the factors for the Acceptance of ERP Systems and Financial Performance. It was establishes that implementation of ERP is directly linked with communication effectiveness in the implementing organizations and had significantly reduced customer complaints and improved customer relations significantly. The study further recommended that ERP deployment should be undertaken when sufficient critical success factors are addressed to position an institution favorably in successfully implementing an ERP system and that continuous monitoring of communication interfaces conducted over ERP platforms to provide efficiency and reliability and avert would be system downtimes.

Study on impact of using an ERP system on organizational processes and individual employees conducted by Spano\& Bello (2015) revealed that ERP can enhance customer service among the internal customers (employees). ERP enhances flow of information and improves efficiency and effectiveness in internal business process therefore facilitating employees' work hence improving their attitude towards work. Organizations decide to implement ERPs solutions to improve the performance of current operations, to integrate data and systems, and to prevent a competitive disadvantage or a business risk from becoming critical (Spano \& Bello, 2015). The study conducted by Zaglago et al. (2013) on the impact of culture in ERP system implementation revealed that successful implementation of an ERP system in any organization is affected by the culture within the organization.

The study established that some cultural factors may inhibit the organizations from prioritizing their implementation efforts, and resources in order to achieve successful ERP implementation process. These cultural factors include; management culture and organizational culture. The study in addition recommended that organizations need to assess ERP suitability and devise mechanisms to mitigate the impact of cultural misfit, and increase value from relatively expensive ERP investments. The study by Ndungu \& Wangombe (2012) 
on ERP implementation experience in selected public universities in Kenya revealed that people are critical in implementation of ERP. Inadequate internal and external human resources were cited as critical factors affecting implementation of enterprise systems in the selected public universities. The study reported that use of ERP requires continuous review enhance success of its implementation. Preventive maintenance procedures and debugging should be conducted to provide efficiency and reliability. With service delivery being one of the core reason for adoption of ERP, quality of service delivery should be responsive to institutional needs while providing operational advantage to respective institutions (Michael, 2013).

\subsubsection{Single Purpose Interface}

Single purpose interface is designed for specific functions within the organization. The interface is designed to carry out activities of specific departments. Single purpose ERP interface as a system requires integration of the various functional parts (modules). It requires free flow of information across the organization (Institute of Management Accountants, 1999). There is need to develop a central data base and develop systems for information access to data in real time, data storing and retrieving processes in an enterprise-wide database, and management and analysis functionalities (Spano, 2015).

The modules are developed based on the key business functional areas; production, sales, marketing, human relations and finance and accounting (Dubey, 2007). According to Tadinen (2005) indented seven main benefits of implementation of single purpose interface. These benefits include; improved firm's performance, reduced inefficient manual processes, integrated, enterprise wide common tools and processes, reduced costs through improved enterprise efficiency and computerization, improved logistics, production scheduling, customer service and customer responsiveness, enterprise-wide data visibility, reporting and decision support and ability to manage the extended enterprise of suppliers, alliances and customers in an integrated manner. In addition, single purpose interface leads to improved human resource management, enhances supply chain management, improved customer relations management, enhances finance management and in turn improved customer satisfaction, improved maintenance, enhanced market access and e-business (Umble et al., 2002). Study by Davis (2004) on 'Perceived Effects of ERP on Jobs and Work in a Contact Center' revealed that introduction of an ERP customer care software module into a company's contact center had significant influence on service delivery. The study revealed that introduction of customer focused ERP module can significantly increase accuracy, enhance relationship between functional areas of an organization and lead to development of new service capabilities.

Similar study by Gans et al (2003) on ERP and human resource operations revealed that use of ERP modules dedicated to human resource functions lead to enhanced efficiency and control in human resource operations.
According to Kennrley \& Neely (2001), single purpose ERP interface is intended to provide standard application programs that provide support the execution of certain business activities. As the business activities are carried out through the interface, integration between the various functional areas in the organization is integrated. This is done through common data processing and communications protocols.

Study conducted by Spano\& Bello (2015) revealed that ERP system can enhance customer service among the internal customers (employees). Human resource dedicated ERP interface enhances flow of information and improves efficiency and effectiveness in internal business process therefore facilitating employees' work hence improving their attitude towards work. This translates into motivated employees who not only enhance productivity of the organization but also translate the satisfaction to external customers who come to the organization (Kennerley, 2001).

A study on factors for the acceptance of ERP Systems and financial performance reveled that ERP interface for accounting and finance operations is directly associated with improved revenue collection and finance control. Adoption of ERP system in the for finance operations enhances quality of service and standards since user need measured accurately. The study concluded that benefits which users receive from ERP system can also lead to significant financial improvements of the organization thereby enhancing overall performance of the organization. The study recommended that research be conducted to examine the contribution of ERP within the canon of financial performance.

The future research direction needs to ensure that although user satisfaction, training and other issues are important, the ultimate decision factor in the success or failure of a system is the financial returns which an particular ERP system generates' (Bazhair, 2015). ERP interfaces that are dedicated for specific business activities have specific benefits based on their functions. The systems can integrate various functions within the organization and unify them into a single unified database. Specific ERP interfaces dedicated for functions such as; human resource management, supply chain management, customer relations management, logistics management, warehouse management have the advantage of enhancing the activities in the various functions. Successful implementation of single purpose ERP interfaces can enhance continuous flow of information; improve efficiency, performance, tracking, forecasting and improved customer service and satisfaction (Musyoka, 2012).

\subsubsection{Public Procurement Oversight Authority (PPOA)}

A review in the public procurement in Kenya conducted in 1999 revealed that public procurement was characterized by non-uniform procurement procedures, unclear dispute resolution mechanism, poor records management etc. to remedy the country from such a crude system, The Public Procurement and Disposal Act, 2005 created Public Procurement Oversight Authority. The oversight authority was formed to ensure procurement procedures established under. The Act are complied with, to monitor the procurement 
system and reporting on its overall functioning, to initiate public procurement policy and to assist in the implementation and operation of the public procurement system (Public Procurement Oversight Authority, 2016). Public organizations like GDC are expected to carry out all procurement activities according to the provision of Public Procurement and Asset Disposals Act, 2015. They are similarly expected to comply with regulations of PPOA. As such, PPOA is expected to play a mediating role on adoption of innovative procurement activities and the expected outcome.

\subsubsection{Concept of Service Delivery}

As pointed out by Wernerfelt et al. (1996), customers are the starting and end point of an organization. He points out that organizations need customers to survive and therefore customers must be at the center of everything and organizations must strive to create and give value to customers. While organizations are expected to deliver quality and optimal service to customers, the expectations of customers are varied. It is therefore important that the necessary steps are taken so that customer's needs are understood and delivered (Riordan, 2003).

Customer service delivery is the provision of service to customers before, during and after a purchase of physical product or delivery of a service. The concept of customer service delivery has become a matter of concern to every manager. Henry (2000) in his report on customer service in delivery of health services established that while all agencies claim that quality care and patient satisfaction remain important, the emphasis on cost control and limitation of services is unmistakable. He established that management of customer service; both expected and implied must be delivered.

\section{Methodology}

This study adopted descriptive research design and was a case study. Descriptive study determines whether or relationship exists between two or more quantifiable set of variables. In addition, this study adopted a case study design. Case study design involves; designing a case study, collecting the study's data, analyzing the data, presenting and reporting the research results (William, 2006).

The research targeted majorly qualitative data. Qualitative data is a categorical measurement expressed not in terms of numbers, but rather by means of a natural language description (Mugenda \& Muganda, 2013). Five points Likert scale was used to quantify facilitate recording of the qualitative data numerically in order to enhance data collection and analysis. The collected data with then be analyzed descriptively and inferentially.

To ensure adequate representation of employees in every department, the researcher used stratified random sampling technique to determine sample size for every department. The researcher decided on use 86 percent of the target population as a sample.

The sample size was therefore obtained as shown below;
Sample Size $(n)=(86 / 100 * 115)=99$ respondents

The formula below was then used to determine sample size for every department;

$\mathrm{nh}=(\mathrm{Nh} / \mathrm{N}) * \mathrm{n}$

Where nh-sample size for stratum $h$

Nh-the population size for stratum $h$

$\mathrm{N}$-total population size

n-total sample size.

i.e. Procurement $(\mathrm{nh} 1)=(30 / 115 * 99)=26$

Stores $(\mathrm{nh} 2)=\left(20 / 115^{* 99}\right)=17$

Registry $(\mathrm{nh} 3)=(15 / 115 * 99)=13$

Finance $(\mathrm{nh} 3)=(30 / 115 * 99)=26$

$\operatorname{ICT}($ nh4 $)=(20 / 115 * 99)=17$

The distribution of sample elements as presented in Table 1.

Table 1. Distribution of Sample Elements.

\begin{tabular}{llll}
\hline No. & Department & Number of Employees (N) & Sample Size (n) \\
\hline 1 & Procurement & 30 & 26 \\
2 & Stores & 20 & 17 \\
3 & Registry & 15 & 13 \\
4 & Finance & 30 & 26 \\
5 & ICT & 20 & 17 \\
& Total & 115 & 99 \\
\hline
\end{tabular}

Data on the research variables were analyzed descriptively using mean and standard deviation. Relationship between implementation of ERP and service delivery was analyzed through regression analysis.

\section{Research Findings, Conclusions and Recommendations}

To achieve the objectives of the study, hypothesis testing was conducted using one way ANOVA. For each hypothesis, the composite value of the dependent variable was obtained. The metrics of the independent variables were then regressed against the dependent variable. Significance level (p) of 0.05 was used whereby where $p$-value obtained in the analysis was greater or equal to 0.05 , the null hypothesis was accepted.

\subsection{Influence of Business to Suppliers Interface on Service Delivery}

The first objective of the study was to determine the influence of Business to Suppliers Interface on Service Delivery. Consequently, the first hypothesis was $\mathrm{Ho}_{1}$ : Business to Suppliers Interface does not have significant influence on Service Delivery in procurement department of GDC, Nakuru.

ANOVA test produced results presented in Table 2 .

Table 2. Influence of Business to Suppliers Interface on Service Delivery.

\begin{tabular}{|c|c|c|c|c|c|c|}
\hline Model & & Sum of Squares & Df & Mean Square & $\mathbf{F}$ & Sig. \\
\hline \multirow{3}{*}{1} & Regression & 16.173 & 3 & 16.173 & 37.096 & $.000^{\mathrm{a}}$ \\
\hline & Residual & 34.007 & 76 & .436 & & \\
\hline & Total & 50.180 & 79 & & & \\
\hline
\end{tabular}

a. Predictors: (Constant), Business to Suppliers Interface 
b. Dependent Variable: Service Delivery

From table 2, $\mathrm{F}(3,76)=37.096$ and $\mathrm{P}=0.000(<0.05)$ reveal that Business to Suppliers Interface has statistically significant influence on Service Delivery. The first hypothesis was therefore not accepted and conclusion was made that Business to Suppliers Interface has significant influence on Service Delivery in procurement department of GDC, Nakuru.

\subsection{Influence of Business to Customers Interface on Service Delivery}

The second objective of the study was to establish the influence of Business to Consumers Interface on Service Delivery. To achieve the objective, the study tested the hypothesis; Ho2: Business to Consumer Interface does not have significant influence on Service Delivery in procurement department of GDC, Nakuru. The findings were as presented in Table 3.

Table 3. Influence of Business to Customers Interface on Service Delivery.

\begin{tabular}{|c|c|c|c|c|c|c|}
\hline Model & & Sum of Squares & Df & Mean Square & $\mathbf{F}$ & Sig. \\
\hline \multirow{3}{*}{1} & Regression & 25.160 & 3 & 25.160 & 47.440 & $.000^{\mathrm{a}}$ \\
\hline & Residual & 25.017 & 76 & .325 & & \\
\hline & Total & 50.178 & 79 & & & \\
\hline
\end{tabular}

a. Predictors: (Constant), Business to Customers Interface

b. Dependent Variable: Service Delivery

From Table 3, F $(3,76)=47.440$ and $p=0.016(<0.05)$ imply that Business to Consumer Interface has significant influence on Service Delivery. The second hypothesis of the study was thus no accepted and conclusion made that Business to Consumer Interface has significant influence on Service Delivery in procurement department of GDC, Nakuru.

\subsection{Influence of Single Purpose Interface on Service Delivery}

The third objective was to determine the influence of Single Point interface on Service Delivery. To achieve this objective, the study tested the hypothesis; $\mathrm{Ho}_{3}$ : Single Purpose interface does not have significant influence on Service Delivery in procurement department of GDC, Nakuru. The findings were as presented in Table 4.

Table 4. ANOVA on Single Purpose Interface and Service Delivery.

\begin{tabular}{|c|c|c|c|c|c|}
\hline Mode & & Sum of Squares & Df & Mean Square & Sig. \\
\hline \multirow{3}{*}{1} & Regression & 7.785 & 3 & 7.785 & $14.140 .000^{\mathrm{a}}$ \\
\hline & Residual & 42.393 & 76 & .551 & \\
\hline & Total & 50.178 & 79 & & \\
\hline
\end{tabular}

a. Predictors: (Constant), Single Purpose Interface

b. Dependent Variable: Service Delivery

From Table 4, F $(3,76)=14.140$ and $\mathrm{p}=0.000<0.05$ revealed that Single Purpose interface has significant influence on Service Delivery. The third hypothesis was equally not accepted and conclusion was made that Single
Purpose interface has significant influence on Service Delivery in procurement department of GDC, Nakuru.

\subsection{Combined Influence of ERP on Service Delivery}

The last objective of this study was to establish the combined effect of business to suppliers interface, business to consumers interface and single purpose interface on Service Delivery. The study equally tested the hypothesis; $\mathrm{H}_{04}$ : business to suppliers interface, business to consumers interface and single point interface collectively do not have significant influence on Service Delivery in procurement department of GDC, Nakuru. The findings were as presented in Tables 5 .

Table 5. Combined Influence of ERP on Service Delivery.

\begin{tabular}{lllllll}
\hline \multicolumn{1}{l}{ Model } & Sum of Squares & Df & Mean Square & F & Sig. \\
\hline & Regression & 20.444 & 3 & 6.815 & $33.968 .000^{\mathrm{a}}$ \\
1 & Residual & 21.609 & 76 & .284 & \\
\hline & Total & 42.053 & 79 & & \\
\hline
\end{tabular}

a. Predictors: (Constant), Single Purpose Interface, Business to Customer Interface, Business to Supplier Interface

b. Dependent Variable: Service Delivery

From Table 5, F $(3,76)=33.968$ and $p=0.000(<0.05)$ imply that Single Purpose Interface, Business to Customer Interface, Business to Supplier Interface collectively have significant influence on service delivery. The forth hypothesis; $\mathrm{Ho}_{4}$ : Business to suppliers interface, business to consumers interface and single point interface collectively do not have significant influence on service delivery in procurement department of GDC, Nakuru is therefore not accepted on this basis and conclusion made that business to suppliers interface, business to consumers interface and single point interface collectively have significant influence on Service Delivery in procurement department of GDC, Nakuru.

\subsection{Multiple Regression Analysis}

Multiple regression analysis was conducted to obtain the regression model for the study. The findings were as presented in tables below;

Table 6. Model Summary.

\begin{tabular}{lllll}
\hline Model & R & R Square & Adjusted R Square & $\begin{array}{l}\text { Std. Error of the } \\
\text { Estimate }\end{array}$ \\
\hline 1 & $.697^{\mathrm{a}}$ & .486 & .466 & .53322 \\
\hline
\end{tabular}

a. Predictors: (Constant), Single Purpose Interface, Business to Customer Interface, Business to Supplier Interface

From Table 6, R square measures the combined explanatory power (influence) of Single Purpose Interface, Business to Customer Interface and Business to Supplier Interface on Service Delivery. R square $=0.486$ implies that Single Purpose Interface, Business to Customer Interface, Business to 
Supplier Interface explain up to $48.6 \%$ of the changes in service delivery. This implies that the three variables are strong determinants of service delivery.

Table 7. ANOVA Table.

\begin{tabular}{|c|c|c|c|c|c|c|}
\hline Model & & Sum of Squares & Df & Mean Square & $\mathbf{F}$ & Sig. \\
\hline \multirow{3}{*}{1} & Regression & 20.444 & 3 & 6.815 & 33.968 & $.000^{\mathrm{a}}$ \\
\hline & Residual & 21.609 & 76 & .284 & & \\
\hline & Total & 42.053 & 79 & & & \\
\hline
\end{tabular}

a. Predictors: (Constant), Single Purpose Interface, Business to Customer Interface, Business to Supplier Interface

b. Dependent Variable: Service Delivery

Table 7 measures significance of the overall explanatory power of the three indicators; Single Purpose Interface, Business to Customer Interface and Business to Supplier Interface on Service Delivery. $\mathrm{P}=0.000<0.05$ implies that the overall influence is statistically significant.

\subsection{Regression Model}

From the regression analysis, Table 8 was obtained

Table 8. Table of Coefficients.

\begin{tabular}{llllllr}
\hline \multirow{2}{*}{ Model } & \multicolumn{2}{l}{$\begin{array}{l}\text { Unstandardized } \\
\text { Coefficients }\end{array}$} & $\begin{array}{l}\text { Standardized } \\
\text { Coefficients }\end{array}$ & Sig. \\
\cline { 2 - 5 } & B & Std. Error & Beta & \\
\hline & .883 & .406 & & 2.176 .033 \\
\hline $\begin{array}{l}\text { (Constant) } \\
\text { Business to }\end{array}$ & .451 & .121 & .486 & 3.744 .000 \\
$\begin{array}{l}\text { Suppliers Interface } \\
\text { Business to } \\
\text { Customers }\end{array}$ & .163 & .102 & .208 & 1.589 .016 \\
$\begin{array}{l}\text { Single Purpose } \\
\text { Interface }\end{array}$ & .210 & .076 & .242 & 2.777 .007 \\
\hline
\end{tabular}

a. Dependent Variable: Service Delivery

From Table 8, the following regression model was developed for the study;

$\mathrm{Y}=0.883+0.451 \mathrm{X}_{1}+0.163 \mathrm{X}_{2}+.210 \mathrm{X}_{3}$

Where; $\mathrm{Y}$ - Service delivery

$\mathrm{X} 1$ - Business to Business Interface

$\mathrm{X} 2$ - Business to Customer Interface

X3 - Single Purpose Interface

\subsection{Conclusions}

The first objective of the study was to determine the influence of Business to Suppliers Interface on Service Delivery. From the research findings, it was concluded that Business to Suppliers Interface has statistically significant influence on Service Delivery. According to Musyoka \& Kwasira (2012), adoption of ERP business to supplier interface reduces transaction and lead time. In addition, it facilitates sourcing of the right product and providing such products in time at the right cost. According to Bagranoff \& Brewer (2003), business to supplier interface facilitates real time flow of information between business and suppliers thereby fostering supplier relations which are critical in sustained service delivery.

The second objective of the study was to establish the influence of Business to Consumers Interface on Service Delivery. From the research findings, it was concluded that Business to Consumer Interface has significant influence on Service Delivery in procurement department of GDC, Nakuru. Business to customer interface enhances flow of information and improves efficiency and effectiveness in internal business process therefore facilitating employees' work hence improving their attitude towards work (Spano \& Bello, 2015). It enhances management of customer complaints thereby reducing customer dissatisfaction (Hedman\&Borell, 2003).

The third objective was to determine the influence of Single Point interface on Service Delivery. From research findings, conclusion was made that Single Purpose interface has significant influence on Service Delivery in procurement department of GDC, Nakuru. Single purpose interfaces provide enterprise wide common tools and processes, reduced costs through improved enterprise efficiency and computerization, improved logistics, production scheduling, customer service and customer responsiveness (Umble et al., 2002). Single purpose interfaces enhance relationship between functional areas of an organization and lead to development of new service capabilities (Gans et al., 2003).In addition, it provides continuous flow that improves efficiency, performance, tracking, forecasting and improved customer service and satisfaction (Musyoka, 2012).

The last objective of this study was to establish the combined effect of business to suppliers interface, business to consumers interface and single purpose interface on Service Delivery. From the findings, it was concluded that Single Purpose Interface, Business to Customer Interface, Business to Supplier Interface collectively have significant influence on service delivery in procurement department of GDC, Nakuru.

\subsection{Recommendations}

Organizations should adopt Business to Suppliers Interface as one of the initiatives towards improving service delivery. Adoption of Business to Suppliers Interface should be made strategically and deliberately and should be backed with management support in availing required resources, training and creating appropriate organizational culture.

Business to Customers Interface is a crucial determinant of service delivery in both service and manufacturing organizations. As such, management of such organizations should adopt Business to Customers Interface in handling customers and customer relations. Such interfaces should adopt to handle customer complaints and problems as they provide real time solution.

Manufacturing and service organizations should adopt single purpose ERP interface in their internal operations as such interfaces integrate operational areas and allow information flow that is critical in service delivery. Constant training system must be put into place to ensure stakeholders understand the purpose and their roles in the interface. 
Combination of all the interfaces of ERP should be adopted in GDC to integrate procurement department, suppliers, customers and the user department for effective service delivery in the organization.

\subsection{Suggestion for Further Studies}

From the study findings; the following areas are recommended for further studies; firstly, further study should be conducted to establish the role of organizational culture in adoption of ERP interfaces. Secondly, further study should be done to develop a theory that would explain the direct link between ERP and service delivery. Lastly, a study should be conducted to establish whether there are specific determinants of ERP adoption unique for manufacturing and service organizations.

\section{References}

[1] Aberdeen Group. (2005). Best Interface in E-Procurement: Reducing Costs and Increasing Value through Online Buying. Aberdeen Group.

[2] Akae, Y. (2014). Diffusion of Innovation Theory and an Implementation on Enterprise Resource Planning Systems. International Journal of Business and Management, 9 (4), 92-114.

[3] Bagranoff, N. A., and Brewer, P. C. (2003). PMB Investments: An Enterprise System Implementation. Journal of Information Systems, 17 (1) 85-106.

[4] Balderstone, S. (2015). A Review of Goldratt's Theory of International Literature Constraints (TOC) - lessons from the. New Zealand: Victoria University of Wellington.

[5] Barnard, A. (2015). What is Theory of Constraints (TOC)? UK: Goldratt Research Labs.

[6] Bateman, A. (2015). Service user Involvement \& Purchasing. Retrieved February 24, 2016, from Ability to Achieve:

[7] Bazhair, A. (2015). Factors for the Acceptance of Enterprise Resource Planning (ERP) Systems and Financial Performance. Journal of Economics, Business and Management, 3 (1), 1-10.

[8] Care Institute of Public. (2011). Service User Involvement; Alcazar Court. London: London Borough of Enfield.

[9] Chad, W. Autry, M. (2016). Achieving Supply Chain Integration: Connecting the Supply Chain Inside and Out for Competitive Advantage. New Jersey: Pearson FT Press.

[10] Ching Yeh, S. (2005). Exploring internal and external service chains of electronic government services. Taiwan Association, $1-16$.

[11] CIPS. (2013). How to Prepare and Evaluate Tenders. UK: CIPS.

[12] Davis, C. (April 2004). A Macroergonomics Perspective on Customer Interaction Centers. 13th Annual Conference of the International Association (pp. 1-7). IAMOT.

[13] Department of Treasury and Finance. (2014). Guidelines for Tender Evaluation using Weighted Criteria for Building Works and Services. Australia: Department of Treasury and Finance.
[14] Department of Treasury and Finance, Australia. (2015). Guidelines on Tender Evaluation using Weighted Criteria for Building Works. Australia: Department of Treasury and Finance.

[15] Desai, J. A. (1986). Purchase Involvement of New Car Buyers: A Descriptive Study. American Journal of Business, 8 (2) pg 13-20.

[16] Defid. (2011). Procurement Best Practice for Civil Society Organisations. DFID; Department of International Development.

[17] Dubey, A. (2007). Delivering software as a service. Talco: The McKinsey Quarterly.

[18] Federal Transit Administration, U.S. Department of Transportation. (2015). Federal Transit Administration. Retrieved 2015, from U.S. Department of Transportation:

[19] Fitzgerald, G. (2006). A Practical Guide For Procurement Planning And Management Of Strategic Public Health Supplies. Washington

[20] Fleming, N. (2014). B2B Companies: Do You Know Who Your Customer Is? Business Journal, 2 (1)11-19.

[21] Ford, H. (2000). Customer Service. London: Jones and Bartlett Publishers.

[22] Gans, G. (2003). Telephone call centers: Tutorial, review, and Research prospects. Manufacturing, 5: 79-141.

[23] Geothermal development Company. (2016). Powering the Vision. Retrieved May 12, 2016, from Company, Geothermal development:

[24] Goldratt, E. (1990). That Is This Thing Called the Theory of Constraints. Great Barrrington: The North River Press.

[25] Hall, R. (2014). General Guide to Writing Specifications. Suffolk: Suffolk County Council.

[26] Hebert, D. (2016). Conflicts Between ERP Systems and Shared Services Can Inhibit Return on Investment. London: Answerthink Inc.

[27] Hedman, J., \& Borell, A. 2003. ERP Systems Impact on Organizations. In Grant, G. (Ed.), ERP \& Data Warehousing in Organizations: Issues and Challenges. Hershey, PA.: IRM Press.

[28] Hertzog, A. M. (2008). Considerations in Determining Sample Size for Pilot Studies. Research in Nursing \& Health. 31 (2), 180-191

[29] Humphreys, C. P. (1998). Improving Public Service Delivery. Ireland: Institute of Public Administration.

[30] Institute of Management Accountants. (1999). Theory of Constraints; Management Systems Fundamentals. Montvale: Institute of Management Accountants.

[31] Interagency Procurement Working Group. (2012). UN Procurement Practitioner's Handbook. UK: United Nations.

[32] Joshi, A. (2010). Service Delivery; Review of Impact and Effectiveness of Transparency and Accountability Initiatives. UK: Transparency and Accountability Initiatives.

[33] Kakwezi, P. (2010). Procurement Process and Performance, effeciency and effectiveness of procurement function. Kampala: Makerere University Business School. 
[34] Kalms, B. (1990). Procurement Guidence: Developing Specification. Queensland: The Commonwealth of Australia (Department of Administrative Services Purchasing Reforms).

[35] Kennerley, M. (2001). Enterprise Resource Planning: Analysing the Impact. Integrated Manufacturing Systems, 103-113.

[36] Kiage,O. (2013). Factors Affecting Procurement Performance: A Case of Ministry of Energy. International Journal of Business and Commerce, 3 (1), 54-70.

[37] Makabira, K. (2014). Role of Procurement Interface on the Performance of Corporate Organizations in Kenya: A Case Study of Kenya National Police Service. International Journal of Academic Research in Business and Social Sciences, 4 (10), 369-385.

[38] Michael,S. (2013). Impact of ERP System in Health Care. International Journal of Academic Research in Business and Social Sciences, 3 (12), 102-418.

[39] Mikalefa, P. (2013). Investigating the Impact of Procurement Alignment on Supply Chain Management Performance. Procedia Technology, 9, 310-319.

[40] Muma, B. (2014). Green Supply Chain Management and Economic Performance: A Review of Tea Processing Firms in Kericho and Bomet Counties, Kenya. International Journal of Science and Research, 3 (11), 2462-2467.

[41] Musyoka, M.\& Kwasira, J. (2012). Effect of Enterprise Resource Planning in Enhancing Service Delivery in the Procurement Function in Public Universities in Kenya, A Case of study of Egerton University- Njoro, Kenya. International Journal of Science and Research, 3 (10), 37-43.

[42] Mutai, J. (2016). Effects of Supplier Evaluation on Procurement Performance of Public Universities in Kenya. International Journal of Economics, Finance and Management Sciences, 4 (3) 98-106.

[43] Ndungu, P. (2015). An Evaluation of ERP Systems Implementation Experiences for Selected Public Universities in Kenya. Nairobi: JKUAT.

[44] Ndungu, W. (2012). An Evaluation of ERP Systems Implementation Experiences for Selected Public Univeristies. Nairobi: University of Nairobi, Press

[45] Ndungu, P. (2015). An Evaluation of ERP Systems Implementation Experiences For Selected Public Universities in Kenya. International Journal of Scientific Research and Innovative Technology, 2 (2), 43-56.

[46] New Zeeland Government. (2011). Mastering procurement: A structured approach to strategic procurement. UK: New Zeeland Government.

[47] Njihia, E. (2014). The Effects of Enterprise Resource Planning Systems on Firm's Performance: A Survey of Commercial Banks in Kenya. International Journal of Business and Commerce, 3 (8), 120-129.

[48] Opeyo, J. (2015). Effect of Strategic Supplier Relationship Management onInternal Operational Performance of Manufacturing Firms:A Case of East African Breweries Limited, Kenya. International Journal of Economics, Finance and Management Sciences, 3 (2), 115-124.

[49] Ongachi, J. (2012). Public Procurement in Kenya. Current
Interface and Future Direction. Nairobi: Kenya Institute of Supplies Management.

[50] Onyango, J. (2014). Effects of Procurement Planning on Institutiona 1Performance: A Case Study of Mombasa Law Court. Internation Journal of Science and Research, 3 (11), 446-455.

[51] Oosterom, W. (2009). The road ahead for Service Delivery. Nairobi: PricewaterhouseCoopers.

[52] Oracle. (2015). Oracle Modern Best Practice for Procurement. Retrieved August 27, 2015, from Oracle.

[53] Paul, L. (2006). A Principal-Agent Theory Approach to Public Expenditure Management Systems in Developing Countries. Wachington DC: International Monetary Fund, Press.

[54] Perreau, F. (2015, October 14). The 3 decision making process guiding consumers' purchasing behavior. Retrieved February 24, 2016, from The Consumer Factor decision-making-processes-purchasing-behavior-of-consumer s/

[55] Punch, K. F. (2003). Survey Research: The Basics. London: Sage Publications Ltd.

[56] The Kenya Gazette (2005). The Public Procurement and Disposals Act, 2005. The Kenya Gazette, Nairobi

[57] Rashid, A. (2002). he Evolution of ERP Systems: A Historical Perspective. UK: Idea Group Publishing.

[58] Ricketts, B. (2008). Reaching the Goal: How managers improve a services business using Goldratt's Theory of Constraints. London: IBM Publishers.

[59] Ringold, H. (2012). Citizens and Service Delivery Assessing the Use of Social Accountability Approaches in Human Development. Washington DC: The World Bank.

[60] Riordan, J. (2003). Developing an Effective Internal Customer Servive Ethos. Ireland: Institute of Public Administration.

[61] Robinson, L. (2009). A summary of Diffusion of Innovations. $\mathrm{UK}$ : Amazon.

[62] Rotich, M. (2015). Relationship Between E-Tendering and Procurement Performance Among County Governments in Kenya. Science Innovation, 3 (5): 46-51.

[63] Rotich, M. (2016). E-Sourcing, E-Maintenance and Public Procurement Performance: A Case of Kericho County. Science Research, 4 (2), 37-42.

[64] Scottish Police Authority. (2008). Scottish Government's Public Procurement Policy Handbook. Scottland: Scottish Police Authority.

[65] Seaman, G. (2012). IT Best Interface; Entreprise Resource Planning and IT Business Transformation. UK: Intel While Paper.

[66] Sitar, U. (2001). Managing Purchasing of Non-Product Related Goods and Services on Horizontal Frictions and Vertical Ignorance. 10th International Annual IPSERA Conference (pp. 131-140). Enschede: University of Twente.

[67] Sivak, M. (2014). Human Resource Technology and Service Delivery Trends in 2014. UK: Information Service Group. 
[68] Spano, A. (2015). The impact of using an ERP system on organizational processes and individual employees. Cagliari: University of Cagliari.

[69] Tadinen, H. (2005). Human resources management aspects of Enterprise Resource Planning (ERP) Systems Projects. Sweden: Swedish School of Economics and Business Administration.

[70] Tate, W. (2014, January 9th). The Essential Concepts of Purchasing and Supply Management. Retrieved February 24th, 2016, from Pearson Financial Press.

[71] The World Bank. (2004). World Development Report 2004: Making Services Work for Poor People. Washington, DC: World Bank.

[72] Uganda Delivery of Improved Services for Health. (2003). Uganda Delivery of Improved Services for Health (DISH) Project. Uganda DISH.

[73] Umble, J. H. (2002). Enterprise resource planning: Implementation procedures and critical success factors. Elsevier Science, 146 (2003) 341-357.
[74] United Nations. (2001). Cooperative Delivery of Public Services: Reflections on the Dynamics of Public Sector Private Sector Civil Society Collaboration on Governmental Service Delivery. Marakkech: The Fourth Global Forum on Reinventing Government: Capacity Development Workshops.

[75] USAID. (2013). Procurement Performance Indicators Using Procurement Performance Indicators to Strengthen the Procurement Process for Public Health Commodities. USA: UAID.

[76] Wernerfelt, B. S. (1996). Internal Customers and Internal Suppliers. Journal of Marketing Research, 33 (3), 268-280.

[77] WMO. (2000). The WMO Strategy for Service Delivery. UK: $\mathrm{WMO} / \mathrm{TD} \neg$ No. 1256.

[78] Zaglago, L. (2013). The Impact of Culture in Enterprise Resource Planning System Implementation. Proceedings of the World Congress on Engineering (pp. (1)3-5). London: WCE. 